'neotenism' (persistence of embryonal forms) recently observed among the Urodela find at least a partial explanation in the artificial transformation of the axolotl as here described: for it has been shown that the tendency to continued development can be suppressed by suitable influences; and such influences may make their appearance naturally, and involve a persistence of the larval condition.

The importance of this series of investigations on the primitive transit of the vertebrates from the water to the land has been already pointed out. It must not be forgotten that the remarkable tenacity of life of the amphibians is a capital element, both in such natural transit and in the successful result of the experiments described. With insects the case is very different: their metamorphosis has in certain cases been suspended, both naturally and experimentally; but all attempts which we have made to induce the reversion of an insect to a larval condition have so far miscarried.

\section{HAS MAN A TAIL?}

Has man a tail? It is a question under dispute. Anatomists have failed to agree as to what constitutes a true tail. A tail is generally understood to be a distinct posterior prolongation of the body, containing a greater or less number of vertebrae. This at once excludes all the cases of a caudal appendix of a fleshy character, such as are found among the rarer abnormalities of human structure. Where does the tail end in front? The comparative anatomist is obliged to designate all the vertebrae behind the sacrum as caudal; so that we are led to the conclusion that the four or five vertebrae of the human coccyx constitute a true though not a protuberant tail. In the embryo, however, during the second month of gestation, the coccy $x$ does form a distinct conical projection, which properly answers to all the requirements of a true tail; so that there can be no question that man has a genuine though rudimentary tail, - a survival from his simian ancestors.

But as man is descended from long-tailed animals, we ought to find evidence in the human embryo of additional vertebrae. Professor Hermann Fol of Geneva has shown (Comptes rendus, 1885) that this is the case. He has found, that, besides the thirty-three or thirty-four vertebrae which persist into adult life, there are other temporary ones. In an embryo five and six-tenths millimetres (about twenty-five days), Fol found only thirty-two vertebrae: Prof. W. His had found thirty-three vertebrae in an embryo a little larger, - seven millimetres. This led Fol to suspect that there might be a still further increase, although in the adult there are only thirty-three or thirty-four vertebrae. He examined two embryos of eight or nine millimetres. One of them was divided into a series of three hundred and twenty sections, and every section was drawn with a camera lucida. Upon counting up the series, it was found that there were thirty-eight vertebrae. Comparison with other embryos satisfied Fol that this condition was perfectly normal. With the exception of the last two, all the caudal vertebrae had a blastema like their anterior fellows. The last two segments were indicated only by the perfectly distinct muscular segments (myotomes). The extremity of the tail was formed solely by the medullary tube, covered only by the skin. The notochord extended almost to the end. The terminal vertebrae have only an ephemeral existence. In embryos of twelve millimetres (six weeks) the thirty-six th to thirty-eighth vertebrae have fused into a single mass. In embryos of nineteen millimetres the last five vertebrae have apparently fused to make the permanent thirty-fourth.

C. S. M.

\section{ETHNOGRAPHY OF ANTARCTIC AMERICA.}

No inhabited land is found within the antarctic circle; and the title which the learned 'secretarygeneral of the ethnographic institution' of France has given to his memoir may therefore seem not strictly warranted. But, in the more general sense in which 'arctic' is applied to climate as synonymous with ' wintry,' the epithet 'antarctic' is sufficiently appropriate to the only region of the southern hemisphere in which the climate is severe enough to exert a controlling effect on the habits and character of the people.

Two years ago a little group of Fuegians, comprising four men, four women, and three children, were brought to Paris, and placed, as so many anthropological exotics, in the 'Garden of acclimation.' There they remained for several weeks, and were visited, of course, by many men of science. M. de LucyFossarieu had already made a study of the tribes and languages of California, and naturally did not neglect the opportunity of examining the natives of this more peculiar and less known region. He saw them frequently, and gained much novel information, which considerably modified the opinions previously entertained respecting this people. He was led to examine the works of earlier observers from the time of Magellan to our own, and to gather from their descriptions, combined with his own observations, a view as complete as can now be attained of the ethnology of the southern extremity of our continent. Such, it appears, was the origin of this memoir, for which students of science are under great obligations to the author. It displays in a marked degree the qualities of clearness of statement, and accuracy of deduction, which distinguish the works of the best French investigators. A summary of its contents, with some additions derived from personal observation of the country and the people, will serve to show the importance of the conclusions which the latest evidence tends to establish.

The Rio Negro, a navigable stream of considerable length, divides Patagonia proper from the territories of the Argentine Republic. From this river to the

Ethnographie de l'Amérique antarctique: Patagons, Araucaniens, Fuégiens. Par P. De Lucx-Fossarieu. Paris, 1884. $4^{\circ}$. 
Straits of Magellan, the country is inhabited by two distinct races, - the Tehuiliches, or true Patagonians, who roam over the vast and arid plains and uplands stretching east of the Andes to the Atlantic; and the Araucanians, who possess the strip of broken and rugged coast-land lying between that mountain chain and the Pacific. The languages of the two races belong to the polysynthetic or incorporative class, but otherwise differ totally, both in grammar and in vocabulary. A like general resemblance, with an equally marked differentiation in special traits, is noted in their other characteristics, physical and moral. The Araucanians, or 'Chileno' Indians, are well known, and have often been described. They are a people of medium stature, well formed, and bearing in their features and color, as well as in their character and habits, the typical characteristics of American Indians. Their energy and unconquerable valor have made them famous; nor only so, but, infused into their half-breed kindred, the Chilian people, these qualities seem destined to secure to that nation the headship of the South-American republics.

The Tehuiliches belong to what D'Orbigny has termed the Pampean race. Their congeners, along with some wandering tribes of Araucanian origin, are spread over the immense treeless plains of the Argentine Confederacy. From them the Tehuiliches, or proper Patagonians, differ mainly in the peculiar traits, bodily and mental, which they owe to the nature of the country they inhabit. This is, for the most part, little better than a stony desert, in which a tree is seldom seen, and only a scanty herbage here and there struggles into existence through the shingle which covers the surface of the land. Some lakes are found, mostly brackish; and a few rivers, fed by the snows of the Andes, traverse the country, and empty into the Atlantic. This monotonous and forbidding region, an antarctic Sahara larger than France, has a population of nomads whose number is supposed not to exceed ten thousand souls. Each individual has therefore a space of more than twenty square miles from which to derive his subsistence. Their food is altogether animal. Guanacoes and ostriches wander over the boundless plains. The Indians, on their fleet horses, run them down, and then capture them readily with their favorite weapon, the well-known bolas. Two balls of stone, or hardened earth, enclosed in leather, held together by a thong, are whirled around the head of the pursuing horseman, and then launched with such force and accuracy as to strike down an animal at the distance of fifty yards. Horse-flesh also, in recent times, enters largely into the Patagonian diet. Like the Eskimo and other tribes of the far north, these natives are fond of fatty substances, which they frequently devour raw. Their strong food, of which there is rarely any lack, and their habits of constant movement in the open air, under a climate severe but not inclement, give them large and robust bodies. The tales of their gigantic stature, so often told and as frequently denied, are thoroughly investigated in this memoir, and with a result which will be interesting to anthropologists.

Careful measurements have been made in recent times, by different observers, of many individuals in various parts of Patagonia. The result is that the mean stature of adults (of both sexes, it would appear) is found to be about 1.78 metres, or five feet ten inches English. " This mean," remarks the author, " may seem rather low; but if we compare it with that of France, which is only 1.65 metres (about five feet five inches), and if we consider that for all humankind the statistics give only 1.70 metres (rather less than five feet seven inches), we shall perceive that this figure represents in reality a very lofty stature, and makes the Patagonians the tallest race of men now existing." Men of six feet French (six feet three and a half inches English) are common among them; and occasionally one is found who reaches two metres, or six feet six and a half inches.

This, however, is not all. The Patagonian, in the upper part of his body, is of a huge build. His trunk and head are large, his chest broad, his arms long and muscular. On horseback, he seems far above the ordinary size of man. When he dismounts, however, it is seen that his legs are disproportionately short and slender: they frequently bend outward. His walk is heavy and lumbering. These are the well-known peculiarities which are found in the Tartars, and in all races of men who spend most of their time, like the Patagonians, on horseback. But it is only a little over two centuries since the horse was introduced into this region. The natives who were first seen chased the swift guanaco and ostrich over their immense plains on foot. Such activity required long, straight, and muscular legs. It is not too much to suppose that the total change in their habits of life, which has occurred since they became a nation of horsemen, has detracted at least two inches from their stature. Adding these lost inches to their present height, we recover the giants who astonished the companions of Magellan, and vindicate the narratives which later writers have discredited. We gain also a notable evidence of the influence of natural causes in modifying the physical characteristics of men.

The moral qualities of the Patagonians, as depicted by the author, are equally in harmony with their surroundings. Their tribes, scanty in numbers and widely scattered, rarely come into collision: wars are consequently infrequent. The more violent passions are seldom aroused. They are neither vindictive nor cruel. Their women are well treated. Like the men, they are good riders, and are, like them, tall, strong, and brave. If need be, they take part in fight beside their husbands and brothers. Children are the objects of singular tenderness. A whole tribe has been known to shift its location merely to satisfy the caprice of a child. The severe trials of their endurance to which youths, on arriving at maturity, are subjected among the fighting tribes of the north, are unknown among these peaceful nomads of the far south. It is hardly necessary to say that slavery does not exist among them, and human sacrifices are unheard of. Horses, in modern times, are frequently killed over the graves of their dead masters, and are sometimes offered in sacrifice to their divinities; 
but the more usual offerings are the clothing and other wares which form their simple household wealth. These are usually hung upon trees, which, perhaps from their rarity, are deemed to have a sacred character.

Leaving these gentle giants, we cross the Straits of Magellan, and encounter what seems at first view to be a very different people. Voyagers who have touched at Tierra del Fuego have been accustomed to represent the natives as a hideous race, $d$ warfish and repulsive in appearance, and degraded in mind and morals almost to the level of beasts. This representation, in our author's view, is not a just one. Accurate measurements show that the average stature of the Fuegians somewhat exceeds five feet five inches English; which, the author remarks, actually surpasses a little that of the Araucanians. This average, of course, includes both sexes. Their squat appearance is due to their mode of sitting, in their canoes and their small dwellings, with their legs doubled under them. The limbs, retained long in this compressed position, become thin and bent. Otherwise the men are well formed, with broad chests and strong arms, and their features are not particularly unsightly. A large face, rather round than oval; prominent cheek-bones; a forehead wide and low; projecting brows; eyes small, black, bright, and restless; a short but nearly straight nose; a wide mouth with thin lips and strong white teeth, - compose a visage somewhat of the Tartar cast, not handsome certainly, but not specially forbidding.

Their nourishment is drawn mainly from the sea, with some variety from land-birds, and from penguins and other water-fowls. They spend much of their time in their canoes, which are ingeniously made of birchbark. The smallest are fashioned from a single piece taken entire from the tree, while the largest are composed of five or more pieces skilfully sewn together, and caulked with a species of resin. The large canoes are sometimes fifteen, and even twenty feet long. For transportation the pieces can be taken apart, and at the end of the portage can readily be rejoined and the caulking renewed. They usually carry a small fire at the bottom of the canoe, on a hearth of hardened clay. Their weapons and means of procuring food are the lance and sling, the harpoon, and the bow, the latter unknown to their Patagonian neighbors. The Fuegian bow is by no means the child's plaything which some voyagers have deemed it, who probably never saw it in use. One of the Fuegians in Paris could send an arrow, with simply a sharpened point of wood, through a board one-fourth of an inch thick at the distance of seventeen yards. Another arrow, discharged at the same distance, was buried so deeply in a tree that it could not be withdrawn without breaking. These arrows are usually pointed with flint, or, where it can be obtained, with glass. In the manufacture of these points, they display much skill. The only instrument employed is a long and narrow bone. The workman, holding this bone in his right hand, takes in his left the bit of flint or glass, which he presses firmly on his knee, and rasps violently with his implement, striking off a small fragment at every blow. Thus breaking away, bit by bit, the edges of the object which he holds, he brings it to the desired shape. Twenty minutes ordinarily suffice to complete the arrow-head. In all their other arts, of which they have not a few, the Fuegians show the same quickness and ingenuity. They have no pottery; but they make rush baskets, drinking-vessels of leather or of bark sewn water-tight, and little bags made of bladder, in which they carry their paints and their tinder. There is nothing in all this which seems to indicate in these natives any intellectual inferiority to the other aborigines of this continent.

The author holds that the Fuegians are mainly of the Araucanian race, but the scanty specimen which he gives of the language of those whom he saw seems rather to connect them with the eastern Patagonians. This, however, is a subject for future investigation. What is clear is, that the difference between them and their northern neighbors is due simply to the difference in their position and surroundings. Inhabiting a broken country, - an archipelago composed partly of marshy plains, and partly of rugged mountains; a region deluged by almost incessant rains, and swept by frequent and. violent storms, - they have, of necessity, ceased to be hunters, and have become a race of fishermen, deriving a scanty and precarious subsistence from the tempestuous seas which encircle them. Scattered in small bands, composed each of a few families, they have no occasion for chiefs, or for a regular form of government. In this respect they resemble the Eskimo; and, like them, they retain, in spite of this isolation, some of the best qualities of social man. They are pacific in temper, are fond of their children, and hold age in much respect. Like the Eskimo, when brought to a civilized country, they display an intelligence and a good disposition which surprise and gratify their hosts.

Every now and then we receive accounts of savages, who, in intellect and moral qualities, as well as in aspect, are but little above the brutes. Unscientific observers, imbued with the pride of race and the prejudices of civilization, or theorists viewing every thing through the colored medium of an hypothesis, who cast upon these savages a hasty glance, pronounce them to be a sort of connecting-link between man and the lower animals. These unfortunate creatures are found at one time in Australia, at another in the Andaman Islands, and again in South Africa. Sometimes they are Negritos in the East-Indian archipelago, and sometimes Botocudos in Brazil. Then comes the patient missionary, or the discerning and impartial man of science, like the author of this memoir, and enables us to see that these despised beings are simply men of like nature and capacities with ourselves - restricted and hampered, of course, by their environment, but capable, under better auspices, of rising to the same level of enlightenment which has been attained by the more favored races. The important truth embodied in the motto of the Société d'ethnographie (surrounding three figures of different race-types) - ' Corpore diversi, sed mentis lumine fratres' - is strikingly illustrated by the facts set forth in this valuable essay. H. HALE. 